\title{
Development of Earthquake Early-warning System and Offline Testing
}

\author{
Yin Cai ${ }^{1,2}$, Baoan $\mathrm{Qu}^{2}$, Rui Zhao ${ }^{1}$, Xiqiang Liu' ${ }^{1}$ \\ ${ }^{1}$ Institute of Geophysics, China Earthquake Administration, Beijing, 100081, China \\ ${ }^{2}$ Shandong Earthquake Agency, Jinan 250014, China
}

Keywords: earthquake early-warning; earthquake location; magnitude estimate; offline testing.

Abstract: In this paper, a set of earthquake early-warning system is designed and implemented, and the key technologies such as earthquake location, magnitude estimation and information release are expounded. Finally, the system is tested by offline. The test results show that system has the characteristics of high precision of location, accurate estimation of magnitude and fast response speed. This has accumulated technical foundation for further implementation of online earthquake warning.

\section{Introduction}

Earthquake Early Warning system (EEWs) is one of new techniques that can effectively reduce earthquake disasters [1]. It uses the principle that the velocity of seismic wave is far less than electromagnetic wave [2]. Through the rapid analysis of the real-time data from seismic monitoring network, the earthquake early warning system release information before the destructive $S$ wave arrive at the early warning target area[3]. It alarms people for emergency avoidance, and at the same time, it can also carry out emergency automatic disposal of the essential lifeline facilities, and the aim of mitigating earthquake disaster is achieved accordingly [4]. Earthquake early warning system has been used in the high-risk areas of several earthquake disasters, such as Japan, Mexico, Turkey, Taiwan and other regions.

China strive to develop earthquake early warning system starting from the May 12, 2008 Wenchuan earthquake [5]. In this paper, based on the present situation of China seismic network, a set of earthquake early warning system has been developed, and three core functional modules with key technologies have been expounded in detail [6]. Finally, the system is offline tested by 30 earthquake cases in China and Japan. The test results are valuable for the next stage of algorithm research and system upgrading.

\section{Development and Methodology}

\subsection{Overview}

The earthquake early warning system is based on the B/S (Browser/Server Architecture) and C/S (Client/Server Architecture) mixed architecture which used Java programming language to implemented cross-platform integration for multiple functional modules. The core part of the system consists 3 subsystems: (1) earthquake dynamic location; (2) real-time magnitude estimation; (3) information instant release. The system supports a variety of real-time seismic and strong motion data from different data collection equipment, and can also simulate the standard EVT or SEED format files into data flow for offline testing. When the system detected $\mathrm{P}$ wave triggered by one of stations in the data stream, the algorithm of dynamic location and real-time magnitude estimation will be started. With the passing of time, more and more data from the trigged station are received. During this period, the warning information is constantly revised, and each steps are sent to the desktop and mobile phone users.

\subsection{Event Location}

In order to meet the requirement of timeliness, we divided the location process into 7 situations depending on propagation law of seismic waves, geometric distribution of seismic stations and the 
arrival order of various seismic phases. For a same event, the arrival times of $\mathrm{P}$ wave and $\mathrm{S}$ wave at station $i$ are recorded as $P_{i}, S_{i} . A_{i}, T_{i}$ indicates the azimuth of the first station and the waiting time of the $\mathrm{S}$ wave respectively. $\mathrm{O}$ represent that data has been obtained and applied to the location process. $\times$ indicate that data has not been obtained or not applied to the location process.

Each situation is described separately, as shown in Table 1. The first situation: only one station receive $\mathrm{P}$ wave; Second situation: only the first station receive $\mathrm{P}$ wave and $\mathrm{S}$ wave; Third situation: only two stations receive the $\mathrm{P}$ wave, but do not receive $\mathrm{S}$ wave; Fourth situation: two stations receive $\mathrm{P}$ wave and the first station receive $\mathrm{S}$ wave; Fifth situation: three stations receive $\mathrm{P}$ waves and no $\mathrm{S}$ wave received; Sixth situation: three stations receive $\mathrm{P}$ waves, and the first station receives $\mathrm{S}$ wave; Seventh situation: using more seismological phases from various stations to locate the earthquake.

TABLE 1. Dynamic location method in seven situations

\begin{tabular}{|c|c|c|c|c|c|c|c|}
\hline Situations & $\mathbf{P}_{1}$ & $\mathbf{P}_{2}$ & $\mathbf{P}_{3}$ & $S_{1}$ & $\mathbf{A}_{1}$ & $\mathbf{T}_{1}$ & Method \\
\hline 1 & $\mathrm{O}$ & $x$ & $x$ & $x$ & $\mathrm{O}$ & $\mathrm{O}$ & $\begin{array}{l}\text { The epicenter is located in the V diagram. The } \\
\text { epicenter is the intersection point between the } \\
\text { azimuth line and the V polygon, or the midpoint of } \\
\text { the intersection line between the azimuth line and } \\
\text { the waiting circle. }\end{array}$ \\
\hline 2 & $\mathrm{O}$ & $x$ & $x$ & $\mathrm{O}$ & $\mathrm{O}$ & $x$ & $\begin{array}{l}\text { The intersection of the azimuth and the arrival } \\
\text { circle in the epicenter. }\end{array}$ \\
\hline 3 & $\mathrm{O}$ & $\mathrm{O}$ & $x$ & $x$ & $\mathrm{O}$ & $x$ & $\begin{array}{l}\text { Using the difference of P wave arrival times } \\
\text { between two stations and P wave velocity, } \\
\text { compute the epicenter hyperbolic equation. The } \\
\text { epicenter is the intersection of hyperbola and } \\
\text { azimuth line. }\end{array}$ \\
\hline 4 & $\mathrm{O}$ & $\mathrm{O}$ & $x$ & $\mathrm{O}$ & $\mathrm{O}$ & $\times$ & $\begin{array}{l}\text { The epicenter calculation method is the same as } \\
\text { situation } 5 . \mathrm{S} \text { wave arrival time is used to } \\
\text { determine the focal depth. }\end{array}$ \\
\hline 5 & $\mathrm{O}$ & $\mathrm{O}$ & $\mathrm{O}$ & $x$ & $\mathrm{O}$ & $x$ & $\begin{array}{l}\text { Using the difference of P wave arrival times } \\
\text { between three stations and P wave velocity, } \\
\text { compute three sets of epicenter hyperbolic } \\
\text { equation. The epicenter is the center of } \\
\text { intersection of three sets of hyperbola. }\end{array}$ \\
\hline 6 & $\mathrm{O}$ & $\mathrm{O}$ & $\mathrm{O}$ & $\mathrm{O}$ & $\mathrm{O}$ & $x$ & $\begin{array}{l}\text { Using } 3 \mathrm{P}+1 \mathrm{~S} \text { phase data and genetic algorithm, to } \\
\text { retrieve epicenter and focal depth. When the } \\
\text { distribution goodness of fit of the station is greater } \\
\text { than the specified threshold, the epicenter range is } \\
\text { calculated by situation } 5 \text { methods, and then the } \\
\text { inversion calculation is carried out. }\end{array}$ \\
\hline 7 & $\mathrm{O}$ & $\mathrm{O}$ & $\mathrm{O}$ & $\mathrm{O}$ & $\mathrm{O}$ & $\mathrm{O}$ & $\begin{array}{l}\text { Using more seismological phases to locate the } \\
\text { earthquake. }\end{array}$ \\
\hline
\end{tabular}

\subsection{Magnitude estimate}

At present, there are two kinds of magnitude estimation methods commonly used in earthquake early warning system in various countries, $P_{d}$ and $\tau_{c}$. $\tau_{c}$ method calculates predominant period of $\mathrm{P}$ wave front 3 seconds data to estimate magnitude. $P_{d}$ method estimates magnitude by measuring the maximum amplitude of the $\mathrm{P}$ wave front for a few seconds. From the statistical point of view, two methods can quickly estimate the magnitude before end of the earthquake rupture process. Countries and regions that have carried out earthquake early warning system research have established corresponding empirical statistical relations by sorting out strong earthquake data in their respective 
area. The development of strong motion observation in China is relatively late. Up to now, there is no relationship has been established for estimating magnitude in China.

In this paper, we collected 308 earthquake cases in China from 2008 to 2014 as basic data for establishing statistical relations of magnitude. In order to ensure the stability of calculation and avoid the impact of separate unstable samples on final result, each case is selected to meet the following 3 conditions at the same time.

1) The focal depth is less than $30 \mathrm{~km}$;

2) There are three stations within epicenter $60 \mathrm{~km}$ range at least;

3) Vertical data are continuous and unbounded for the first three seconds.

There were 42 earthquake cases meeting with the three conditions at same time, including 267 data records. The attenuation of $P_{d}$ is related to the propagation path and radiation pattern. Therefore, we choose records of better epicenter inclusion, thereby reducing the standard deviation of regression relations. The relationship between $P_{d}$ and $M$ fitting linear regression is

$$
\mathrm{M}=0.87 \mathrm{Log}\left(P_{d}\right)+1.44 \log (\Delta)+5.23 \pm 0
$$

The mean value of multiple $\tau c$ from same case is taken as a sample. The relationship between and fitting linear regression is

$$
\mathrm{M}=3.72 \log \tau c+4.70 \pm 0.48
$$

\subsection{Information release}

The earthquake early warning information release consists of two parts: server side and client side. The server side completes real-time push of earthquake early warning information, and the client side acquires early warning information to display and alarm. The client is mainly designed and developed for desktop and mobile users, so we uses WebGIS and Android platform as development environment respectively. Based on the classic three layer architecture design model, the information release module add a service layer, which realized the early warning parameter calculation and data interaction between each other layers. The purpose is to completely decouple data analysis from information release, and provide an extensible service for the future access to the different terminals or the platform users.

WebGIS platform software adopts RIA (Rich Internet Application) as the core technology. We implement anti-serialization processing of JSON packets through Java programming language, and use the HTML5 to realize the superposition of GIS function and earthquake early warning information. The rich client application mode not only reduces the complexity of the system deployment and the computing pressure of the server, but also improves the overall response speed of the system. At the same time, it can realize dynamic update of early warning information without refreshing, and bring better operation experience to users.

Android platform software is based on the original development of Android operating system. ViewStub dynamic layout display technology is used to design the user interface. It effectively reduce the occupation of resources and the delay of information receiving. By invoking map data of open platform, we constructed geographic data resources, and realized superposition and presentation of early warning information, location information and geographic information. Users could customize the content of early warning service, set up interactive mode and information receive mode, so as to meet the needs of earthquake early warning information under various scenarios.

\section{System testing}

We selected 20 earthquakes in China and 10 earthquakes in Japan as testing cases, and the magnitudes range from M4.6 to M8.0. The epicenter distribution map is shown in Fig. 1. Through the offline simulation of each seismic data, the key technologies such as dynamic location, estimate magnitude and real-time information release in earthquake early warning system are comprehensively tested. 

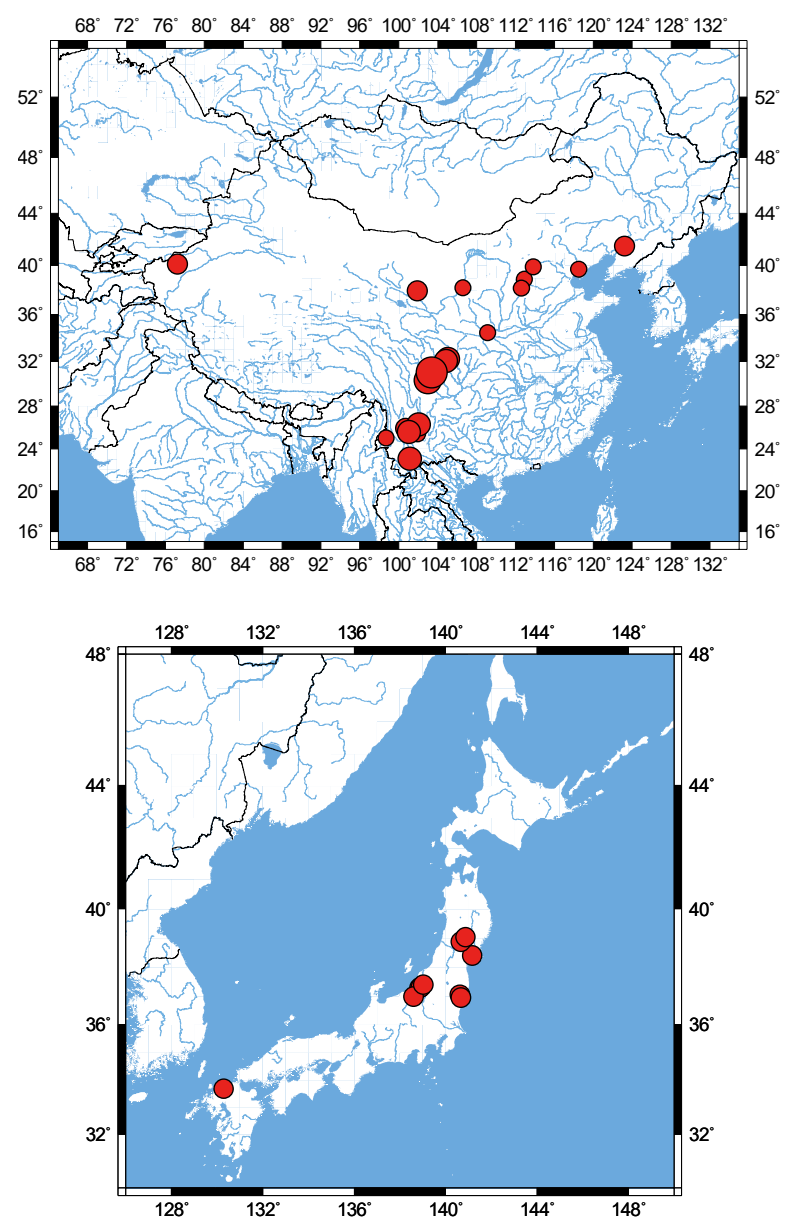

Fig. 1. Events used in the test dataset
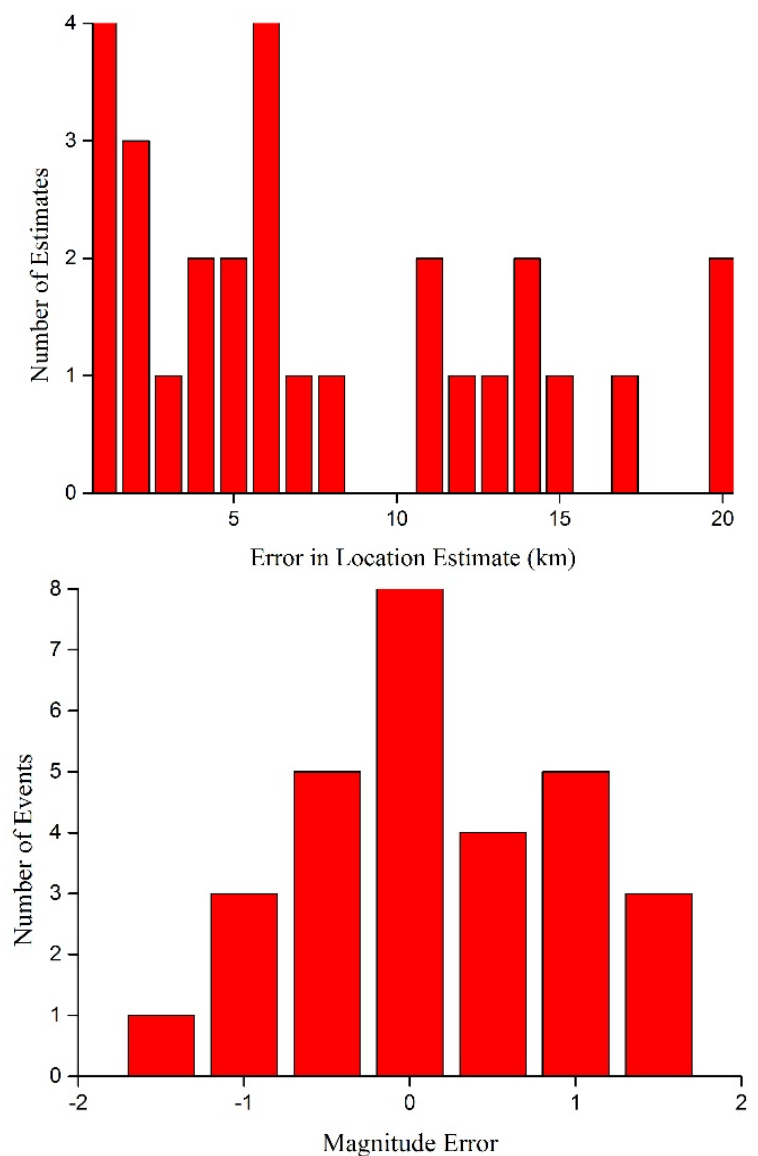

Fig. 2. Histogram of magnitude errors and location errors 
The system starts with the first trigger station, and revising the location result and estimated magnitude automatically with each additional station information. Fig. 2 shows the resulting earthquake early warning system location and magnitude error histograms. The average location error of the 30 earthquake cases is less than $10 \mathrm{~km}$, and the maximum error is $20 \mathrm{~km}$. Using $\mathrm{P}$ wave front three seconds data, the average error of magnitude is less than 1 unit, and the maximum error is 1.5.

Fig. 3 shows an example of WebGIS and Android platform software information release. In order to keep the style of client software unified, the display content and presentation form of WebGIS and Android platform software are basically same. When an event is triggered, the location of user and epicentre are marked on the map. The system shows $\mathrm{S}$ wave diffusion process in a dynamic way, and uses countdown method to alert users to emergency avoidance. In the process of testing, to fully reflect the response time of different network environments, Wi-Fi and 4G wireless network environments are selected for testing. In the Wi-Fi wireless network environment, the average response time of system is $318 \mathrm{~ms}$, and the client can receive $100 \%$ early warning information. In the $4 \mathrm{G}$ environment, the average response time of system is $705 \mathrm{~ms}$. From the system $\log , 3.6 \%$ of the early warning information is pushed twice, the response time of the system is increased to some extent.
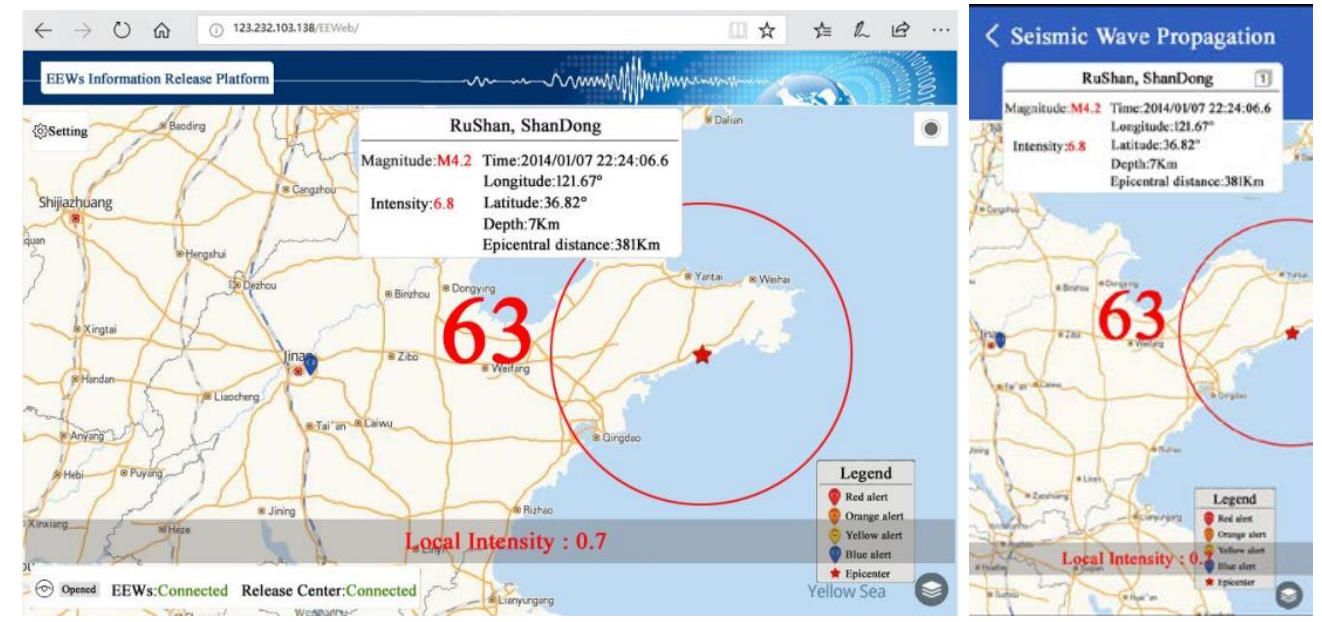

Fig. 3. Example of WebGIS and Android platform software information release

\section{Conclusion}

In this paper, we draw on the current development ideas of various earthquake early warning systems, proposed a new dynamic location method under 7 conditions. Using seismic data in China, we set up the empirical statistical relationship with $\mathrm{P}$ wave data to estimate the magnitude. Finally, the earthquake early warning system software is designed and implemented based on $\mathrm{B} / \mathrm{S}$ and $\mathrm{C} / \mathrm{S}$ mix architecture.

Through offline testing, results show that the system using $\mathrm{P}$ wave data to location epicenter error is less than $10 \mathrm{~km}$, estimated magnitude error is less than 1 unit, and system response time is less than 1 second. Therefore, the system has the characteristics of high precision of location, accurate estimation of magnitude and fast response speed, which can meet the function and performance requirements for earthquake early warning.

\section{Acknowledgement}

The authors wish to acknowledge the entire earthquake early warning project team, many of whom co-developed the system and completed the testing work. This research was supported by the Shandong Provincial Natural Science Foundation, China (ZR2015DQ002). We would like to thank the China Earthquake Networks Center and NIED for providing us with seismic data. 


\section{References}

[1] Emanuele I. Design and implementation of a landslide early warning system. Engineering Geology, 2012, 147-148.

[2] Hakan A, Oguz O, Wu Y M, et al. An alternative approach for the Istanbul earthquake early warning system. Soil Dynamics and Earthquake Engineering, 2011, 31(2): 181-187.

[3] Hsiao N C, Wu Y M, Zhao L. A new prototype system for earthquake early warning in Taiwan. Soil Dynamics and Earthquake Engineering, 2011, 31:201-208.

[4] Iannaccone G, Zollo A, Elia L. A prototype system for earthquake early-warning and alert management in southern Italy. Bull Earthq Eng, 2010, 8(5): 1105-1129.

[5] Kamigaichi O, Saito M, Doi K, Matsumori T, Tsukada S, Takeda K, Shimoyama T, Nakamura K, Kiyomoto M, Watanabe Y. Earthquake early warning in Japan: Warning the general public and future prospects. Seism Res Lett, 2009, 80(5): 717--726.

[6] Nakamura Y. On the urgent earthquake detection and alarm system (UrEDAS)[C]//Proceedings of Ninth World Conference on Earthquake Engineering, 1988, 7: 673--678 